ORIGINAL ARTICLES

\title{
Childbearing and quality of life decisions for women in Taiwan
}

\author{
Shu-Ling Chen ${ }^{1}$, Linda Katherine Jones ${ }^{* 1}$, Merv Jackson ${ }^{2}$ \\ ${ }^{1}$ Discipline of Nursing and Midwifery, School of Health Sciences, RMIT University, Melbourne, Australia \\ ${ }^{2}$ Discipline of Psychology, School of Health Sciences, RMIT University, Melbourne, Australia
}

Received: January 16, 2018

DOI: $10.5430 /$ ijh.v4n1p16
Accepted: February 6, $2018 \quad$ Online Published: February 25, 2018

URL: https://doi.org/10.5430/ijh.v4n1p16

\begin{abstract}
Taiwan has one of the lowest birth rates in the world and is predicted to lead to zero population growth. This study aimed to gain a comprehensive understanding of the personal, social and cultural factors influencing Taiwanese women's motherhood decision making.

Semi structured interviews from first time mothers and theoretical sampling were applied to recruit participants from an antenatal clinic in a large metropolitan hospital from Taipei, Taiwan until data saturation was achieved with 34 women. A number of categories were identified from the data with this paper presenting only the category of "childbearing and the quality of life". Under this category a number of factors were identified that contributed to the decision on whether to have children. This included the couple's financial circumstances, existing pressure from living expenses, childbearing is costly and having children in a responsibility.

Childbearing and quality of life was identified from the data as a crucial factor influencing participant's decision making choices to have children. This was because women wanted to maintain a certain quality of life and needed to then ascertain how much this would be influenced by having children. It is becoming clear that economic development specifically related to materialistic values, has negatively influenced the value people place on having children. Encouraging a return to traditional Taiwanese values as well as orienting people away from materialistic values maybe a way to turn the fertility rate around.
\end{abstract}

Key Words: Taiwan, Low fertility, Decision making, Childbearing, Materialism, Traditional values

\section{INTRODUCTION}

Having children is a very significant event in a woman's life. Taiwanese traditionally believe that to be a mother is the fulfilment of being a woman. Pregnancy means happiness (Youxi: having something is joyful). According to traditional Confucian norms in Chinese culture, a woman is expected to marry and have children; the aim of marriage is to produce new life. ${ }^{[1]}$ Childbearing, therefore, is an important function of womanhood within the context of Chinese culture $^{[1,2]}$ According to cultural traditions, the more children a woman has the happier she will be. This contributed to over-population in Taiwan in the 1960s. Consequently, the government introduced a family planning program in which midwives and nurses played an essential role in reducing the fertility rate. ${ }^{[3]}$ Family planning in Taiwan was a crucial event which had a strong influence on declining birth rate during 1960s-1970s. ${ }^{[4]}$

\footnotetext{
*Correspondence: Linda Katherine Jones; Email: 1.jones@federation.edu.au; Address: School of Nursing, Midwifery and Healthcare, Faculty of Health, Federation University of Australia, Melbourne, Australia.
} 
Despite the strong cultural belief to have children, the birth rate continued to steadily decline. Over the past few decades, the birth rate in Taiwan has decreased every year due to changes in the structure of society, economic status and culture. Government policy and the changing socio-economic and cultural context in Taiwan appears to have affected women's attitudes towards and choice of having a baby in relation to the meaning of their life. ${ }^{[5]}$ According to the Department of Household Registration Affairs Ministry of the Interior ${ }^{[6]}$ the average number of births per woman in Taiwan was 7.040 during the $1950 \mathrm{~s}, 3.705$ in the $1970 \mathrm{~s}, 1.810$ in the $1990 \mathrm{~s}$, and 0.895 in 2010 , indicating that the birth rate is falling much faster than previously forecast. This therefore means that Taiwan has one of the lowest birth rates in the world. A continued reduction in the Taiwanese birth rate has resulted in zero population growth with the birth rate below-replacement level, and will lead to a negative growth in the foreseeable future. It is predicted that according to the Organisation for Economic Cooperation and Development (OECD) a replacement level of 2.1 children per woman is needed to maintain a population. Taiwan is falling far short of this which is of great concern. ${ }^{[7]}$

In an attempt to rectify the falling birth rate, the Taiwanese government incorporated a maternity care policy under the Bureau of National Health Insurance (BNHI) program. ${ }^{\left[{ }^{8]}\right.}$ This program, introduced in 1995, was for universal health insurance coverage to encourage women to have children by decreasing the pregnancy expenses. For example, the BNHI program provides all eligible pregnant women with ten free prenatal care visits combined with comprehensive health examinations and a free birth service, examination and free treatment of pregnancy complications. ${ }^{[8]}$ In addition, the BNHI developed several payment methods due to the rapid growth of medical expenses. For example, in 1995 vaginal birth and caesarean birth were included in the "case payment" method that reimburses inpatient care. Pregnant women can, therefore, receive better maternity care under this policy and substantially reduce the cost of prenatal checks and giving birth.

As well as this, in response to the continued declining birth rate, the Taiwanese government implemented additional incentives to encourage women to have children. For instance, parents can receive educational subsidies for their children. In addition, since 2002, children under the age of three years have received free medical care under Taiwan's BNHI. In addition, the government introduced maternity benefits for working women in 2002 which included eight weeks paid maternity leave, or up to two years unpaid maternity leave. Subsequently an additional incentive strategy had been introduced to include $60 \%$ paid leave for the first six months after

Published by Sciedu Press giving birth. ${ }^{[9]}$ Moreover, the Mega Warmth Social Welfare Program (MWSWP) had been introduced in 2006 to encourage women to have children. This consists of maternity and parental leave benefits, a childcare subsidy system and early children education and care. ${ }^{[10]}$ Childrearing and educational subsidies, day-care facilities and other incentives have also been made available in an attempt to encourage an increase in the population. ${ }^{[9]}$ Thus, the financial burden seems to have been somewhat ameliorated for pregnant women. Despite all of these incentives, they have had a minimal effect on the birth rate.

There may be a number of reasons that help to explain why the fertility rate remains low. This includes the fact that Taiwan is now highly industrialised and modernised and therefore most young women are highly educated and have considerable employment opportunities that they may not want to forsake. Furthermore, women becoming pregnant tend to be negatively discriminated in the workforce In addition, women are marrying later leading to decreased fertility, choosing to have smaller families, ${ }^{[11,12]}$ and responding to the availability of contraceptive services by the government. ${ }^{[11]}$

In Taiwan, in recent years, the low birth rate has become a national issue, which needs to be solved urgently. ${ }^{[13]}$ Despite many studies ${ }^{[13-16]}$ having been conducted from different aspects such as socio-economic status, women's education, child-rearing attitudes and so on, they have appeared to have had little impact on the current situation. Decision-making to having children has been found to be a crucial event in women's life. Culture, ${ }^{[17]}$ religion, ${ }^{[18]}$ socio-economic status, ${ }^{[19]}$ beliefs about childbearing, ${ }^{[20]}$ and the meaning of having children ${ }^{[18]}$ are all been found to be factors that influence when women make a decision to have or not to have children. There is a paucity of research undertaken in this area, especially in Taiwan. Understanding women's influencing factors in decision making to have a child will help to establish appropriate strategies to facilitate them through education or consultation, and to help increase the fertility rate. It is essential, therefore, to explore and describe the influences impacting a woman's decision to have a child from nursing midwifery perspective.

\section{METHOD}

In order to explore the influences on Taiwanese women's decision to have children, a qualitative approach using grounded theory was employed. Qualitative research aims to explore and understand the meaning individuals or groups assign to a social or human problem. ${ }^{[21]}$ Using qualitative research is the most useful where little is known about a topic or a phenomenon. ${ }^{[22]}$ 
All pregnant women attending an antenatal clinic in a large metropolitan general hospital in Taipei, Taiwan, who met the criteria, were invited to participate in the study from February to June 2012. Women who were pregnant, over 20 and Taiwanese born were recruited in order to investigate their decision to have a child. The nurse/midwife briefly explained the purpose of the study to eligible women and provided them with the contact details of the researcher if they wanted to participate in the study. The women then contacted the researcher to arrange a time to be interviewed. Initially participants were selected from a purposive sample of first time mothers, with various education background and aged between 20 to 44 years old. Then theoretical sampling was applied and modified during the process of data collection in order for the concepts and categories to emerge during the constant comparative data analysis. ${ }^{[23]}$ Recruitment continued and interviews undertaken until data saturation had been achieved indicated by obtaining no new information and achieving redundancy. ${ }^{[2]}$ A total of 34 women were interviewed in Mandarin by the researcher.

Participants undertook a semi structured face to face interview lasting 30 to 60 minutes in duration which was audio tape recorded. In addition, the participants completed a demographic survey sheet. The interviews were conducted in a private room in the hospital. Questions for the interview guide were developed from the literature review and asked women what their decision making process involved before deciding to have this child.

Full ethics approval was obtained from RMIT Australia University's Human Research Ethics Committee (56/10) and Human Experiment and Ethics Committee from the hospital in Taipei, Taiwan (00-IRB-003_M). Prior to being interviewed each participant was given a plain language statement and consent form to read and sign. Transcripts were identified numerically and any identifying information removed to ensure confidentiality and anonymity. All National Health and Medical Research Council (NHMRC) ethical guidelines were adhered to.

Interviews were transcribed verbatim and checked with the recordings and then translated into English by the researcher. Constant comparative analysis was then used as an approach whereby every piece of data in the interview transcript was compared with others that may be similar or different from it in order to theorise all possible relationships between the data. ${ }^{[25]}$ The central process of data analysis consisted of coding, including open, axial and selective, undertaken in sequence in order to break down, conceptualise, and integrate the information in new ways. ${ }^{[25]}$ A number of categories were identified from this process. This paper will only dis- cuss the category of "childbearing and the quality of life".

\section{RESUlts}

Under the theme of childbearing and quality of life were a number of factors that contributed to the decision on whether to have children. This included the couples' financial circumstances; existing pressure from living expenses; childbearing is costly; and having children is a responsibility.

\subsection{The couple's financial circumstances}

A couple's financial circumstances were identified from the data as a key factor in influencing many participants' decision to have children or not. Each participant's economic concern about the costs of raising a child varied. Most were aware that economic concern was a very important factor and needed to be considered when they chose to have children. The extent of the influence of the couple's financial circumstances is illustrated in the following:

Economic was the major concern. My husband did not consider having children when he quitted his previous job in order to prepare for taking examination to get license for his career, because he was under heavy economic pressure... (Participant 017)

Needless to say the finical circumstances of the couple also played a large part in determining the number of children they would have:

We will depend on our economic status to decide the number of children that we will have... (Participant 008)

Finding a balance for deciding to have a child as far as financial circumstance for some participants were concerned was to just have a child. In other words, a few participants only considered their own motivation to bear a child:

I never care whether I can afford to bear [children]; I only care whether I want to bear [children] (Participant 032)

This belief was despite the fact that the couple could ill afford to have a child in some cases:

I want to give birth to a child, even though I have heavy economic pressure. (Participant 021)

On the other hand, one participant felt that economic pressure was only used as an excuse by some not to have a child. This demonstrates the importance that some women had on maintaining their quality of life. In other words:

I felt that economic pressure is used as an excuse why they don't give birth to a child; why giving 
birth to a child need to spend a lot of money, all are used as an excuse. It is because their current quality of life will be influenced. I think most of people can afford to bear children. (Participant 021)

The extent of this financial concern is clearly illustrated in this quote which outlines what needed to be taken into consideration with the decision to have children or not:

I am very worry about economic pressure now. You may need to spend some money before the baby is born, and then the cost of childrearing should be unlimited after he/she was born... (Participant 023)

As a consequence, the participants reflected on when the best time to have children would be. The majority of participants planned to have children when they felt that they could afford to bear a child. This was despite the fact that they were living with pressure to have children from many angles, and also the traditional beliefs about childbearing. The decision to have a child, therefore, was when they were ready:

My husband's job was more stable and then he was not under stress... and then we felt that we can prepare [get pregnant]... also, my motherin-law keeps push... so it is the time [to have children]. (Participant 017)

Sometimes the best time to have children was when the couple were more financially stable which meant they had children later on in life. For instance:

I did not want to have children too earlier after I married, but we planned to have children later which will depend on our economic status. After the third year of my marriage, I think it is the time [to have children]. Also, I am 30 years old, so I think I should start to prepare to get pregnant. (Participant 008)

\subsection{Existing pressures from living expenses}

Part of the reason why the decision to have children depended on the financial circumstances of the couple was the existing pressure that existed from living expenses. Daily living expenses, therefore, was seen as an existing pressure for many people. This was contributed to by the fact that Taiwan's society is changing with people desiring to have the latest mobile phone, car and other material commodities of convenience. These have all become perceived necessities for living in today's community and a need rather than a want. Dealing with the invisible pressure from daily living

Published by Sciedu Press expense was identified as adding to the economic burden for some participants. This demonstrates the struggle that some women had between having a child and maintaining their quality of life. The following illustrates the extent of these expenses:

I have to pay NT $\$ 60,000$ [AUD\$2,000] monthly at least for living expense, mobile phone fee, and rental fee and car loan payment. (Participant 004)

Another contributing factor to this was the fact that over the past years in Taiwan, living expenses have increased every year. Many salaries had not increased accordingly however:

... living expense continue increase... when I see my friends bear children... the price of formula milk is different this year comparing last year. Everything is increasing in double price, but salary does not increase... house price rise dramatically... you could not afford to buy a house... (Participant 012)

Housing has become quite expensive in Taipei with most people not being able to afford to buy a house. The following illustrates the consequences of this:

In Taipei, a couple both have jobs, they may spend ten years without spending any money on eating out or buying anything in order to buy a house, and then you have to pay mortgage for whole life. How would you have extra money to bear a child? (Participant 015)

In addition, monthly income was not just spent on childrearing, but also their own parents. Caring for elderly parents within the Taiwanese social context is an issue of filial piety, and providing money to elderly parents is an obligation for children (primarily the sons). In other words:

... After you married, you will have children, mortgage, and your father and mother did not have job, you need to give them some money for their daily living expense. I felt that economic pressure is very heavy with all this together. (Participant 023)

Consequently, some participants identified that they had to work harder in order to save more money and postpone pregnancy due to these economic concerns:

... actually, I planned to have children later... Economic was not stable, and then my job and business were not stable... so pressure is heavy... (Participant 022) 
As shown in the following, some people were concerned about buying a property and therefore postponed having children because they considered it to be costly:

Raising children does cost a lot of money... I did not want to get pregnant before, of course partly because we need to buy a house, I felt that you should have a house, and then have children. My friends ... most of them cannot afford to buy a house, so giving birth [having children] is postponed. (Participant 016)

\subsection{Childbearing is costly}

Having children was also identified by the participants as taking on financial responsibility which in turn affected the quality of life. For some participants' childrearing was viewed as being very costly with children's clothing expense, educational costs and so on. Therefore:

Childbearing is very costly... since you started to bear children [pregnant]. For example, you have to buy special shoes, underwear when you are pregnant; baby's stuffs and so on. These stuffs are necessary accessories; you must purchase... (Participant 018)

The effect of this added financial pressure of having children is illustrated in the following:

I was very worry economic pressure. I spent a lot of money for the baby before he/she was born and then it should be endless expense after children were born. Our economic may better than others, but I felt that economic is an invisible pressure... Diaper, formula powder, and then educational fee when he/she grow up. (Participant 023)

What then added to the financial pressure was the fact that most parents wanted to provide the best for their children, including material things and had to adjust accordingly:

Because we gave the pressure to ourselves in order to provide material to children, so we reduced the desires. Parents always want to provide the best for children nowadays. (Participant 025)

What became clear from the participants was that they wanted a better life for their child then they had and the importance they placed on developing them through education. In addition, they were worried that they could not afford a better life for children:

I start to think about my child's future education issue now, because I want to give him/her better educational environment. (Participant 022)
Parenting was about not only providing food and shelter, but parents also needed to spend money for their children providing 'teaching' now. All of these expenses had increased since they were children themselves and were therefore more difficult to achieve. Therefore, parents needed to increase their income in order to raise children, which meant that they both worked and where then unable to have time to spend with them and teach them:

Children's... no matter educational expense or living environment seems different compared to before. Also, you are afraid that he/she may behind [others], and then he/she may need extra classes after school and so on, it is very stressful actually...then parents have jobs and do not have time to teach them... (Participant 024)

These participants identified how important education of their child was for them. Education is a key value in Taiwanese society and method to change social status and wealth. ${ }^{[26]}$ This belief has led many parents to spend a lot of money on educational expense which was seen as investment in the future of their child:

I am worried that my economic status could not afford better life for him/her [her children]. I hope that I can afford my children to learn more skills and attend private classes after school to reinforce his/her studying. (Participant 014)

Most parents are busy with their jobs and may not have much time to spend with their children; therefore, many of them send their children to after-school tutoring and lessons of various sorts in private schools. This is a common phenomenon in Taiwanese society because most parents want to provide the best for their children, and enhance their competitive ability in order to enter better secondary schools to ensure a better career in the future. Private informal children's schools [outside the normal school system] in Taiwan aims to facilitate elementary school students with their homework or teach them skills such as English, piano, painting, mathematics lessons and so on. If parents are unable to pick up their children after school, the private school can also pick them up. All of this costs extra money:

Childbearing is an extra burden for me. Economic is the major concern, because children must attend extra private classes [such as learning music, English, mathematic and so on] after formal class, otherwise they will not be too competitive with others. This is an extra cost... bearing a child till university at least costly millions dollars. (Participant 004) 
This was in stark contrast to what occurred in earlier generations of parents. Previously the women stayed at home and provided this after school care. In recent times both parents need to work in order to maintain the household budget. The consequence of the children not attending extra classes outside school was clear from the following:

You will worry that he/she [a child's learning] maybe behind other students, and parents are busy with work, so they unable to teach them. My mother taught me after school when I was a child. I did not go for the extra classes after school, excepted I learned some skills [such as piano lesson, dance lesson and so on] from others. However, if the children do not attend extra classes after their school, it seems their learning will behind others, so I will consider these issues. (Participant 024)

\subsection{Having children is a responsibility}

The other part of the quality of life equation identified from the data was that having children added responsibility in a number of ways. Some women identified that they were scared of taking on what they perceived to be a big responsibility for caring for the child. In other words:

I felt that it is very hard to survive in this environment... since you gave birth to a baby, you should have responsibility for him/her... If I do not need to take this responsibility which it is very good, I was expected not to take this responsibility before, because I knew if I choose to have babies, I need to take this responsibility. (Participant 017)

Participants commented that childrearing required parents to take responsibility, spend time to take care of their children and meant that their life had changed as a consequence:

After giving birth to a child, you will have responsibility... (Participant 017)

For some of the participants, they were not prepared to have children because of the added responsibility that this would bring which they perceived would in turn affect their quality of life. This was firstly because of the financial implications as illustrated:

Two people's life is good. My boyfriend felt that if we have children that will change our current life and the quality of life will not be good. Because raising children is very expense. So we did not have motivation to have children at that time. (Participant 027)
The second way that having children affected the quality of life of the couple was the lack of spontaneity that they perceived would result from having children. This quote illustrates the fact that having children was perceived by the participants to mean that they had to stop certain activities. In addition, their quality of life would be affected, because childrearing is inconvenient and parents could no longer be spontaneous:

I like freedom and play. It [having children] will effect on me. I felt that I am very happy and comfortable by myself. I do whatever I want. I like freedom. I like play cards [a kinds of gambling which play cards with friends], I like to go shopping or others. If I have children, I will not be able to do these things. I am scared to be tied, I will be tied by my children (Participant 025 )

The following illustrates various other reasons that the participants identified how their quality of life may be affected by having children:

We had freedom without children. For example, we can go anywhere whenever we want to, but it will be very inconvenient after having children, because we need to concern about children. (Participant 023)

It was clear from the data the extent of the concern that participants had regarding the effect that having children would have on the quality of life:

It is difficult to give birth to and raise a child which means you need to teach and care for $\mathrm{him} / \mathrm{her}$, and then take care of him/her, I felt that I will not able to do it. It is my self-fish thought that I can live a good life by myself, but I could not do it [bearing a child] ... Extra person means extra worry. (Participant 020)

Such was the concern that instead participants commented that they preferred to have pets to children:

... I felt both of us [my husband and I] are very happy, so I never think about giving birth to a child, because giving birth to a child is very trouble, and you have to spend money later... two people are ok. Why do we need to give birth to a child, it is very trouble, just have pets... (Participant 016) 


\section{Discussion}

Participant's financial circumstance was identified in this study as being a key factor needed to be considered when making a decision to have children. Many participants commented that they wanted to be financially stable before deciding the timing of pregnancy. These participants considered whether they had earned enough money in order to provide housing, living expense, or sustaining a pleasant lifestyle as securities in employment equated to access to goods and service for living and raising children. Similar results were found in a study undertaken in Germany by Tolke and Diewald. ${ }^{[27]}$ The authors concluded that economic insecurities were found to be one of the reasons behind postponing the timing of having children. ${ }^{[27]}$

Part of the consideration regarding their financial circumstances was the pressure from day to day living expenses. This is the essence of what can be defined as maintaining the quality of life. Taiwanese consumption patterns have changed due to societal changes. ${ }^{[28]}$ In other words, people are buying more and replacing items rather than repairing them and making do. People tend to want the latest technology piece of equipment, like mobile phones or computers. This has resulted in increased financial pressure to purchase these as they become a "need to have" rather than a "want to have". In fact financial pressure has been identified as one of the major factors which has caused Taiwanese man not to get married ${ }^{[29]}$ This is because of the added expense associated with, not only getting married, but then having children.

The second consideration identified from the data that needed to be factored into in relation to financial considerations was the expense associated with having a child. The costs of a child include expenditures on larger housing, the schooling of the child and of course on goods such as clothes, food and toys and sports equipment. In addition to these child related expenditures, much emphasis in economic theory is placed on the opportunity costs of time spent with the child. ${ }^{[30]}$ Children entail costs in terms of time and time costs money. Specifically in this case, maternal time costs money. On top of this is the goods, or direct expenditure spent on children. Therefore, childbearing costs include direct expenditure and opportunity costs.

What compounded the expense further, which this study demonstrated, was that parents wanted more for themselves and their children then in the past. As previously mentioned, the cost of children has increased, due to the improved standards of living and requirements for increased education, such as extra tutoring after school and music lessons. There is also a perception of the rising costs of education and higher standards of consumption All of this points to the fact that childbearing is costly and has to be factored into the decision making process.

Childbearing and quality of life was identified from the data as one of the crucial factors which influences participates' decision making choices to have children. This was because women wanted to maintain a certain quality of life and needed to then ascertain how much this would be influenced by having children. Women in Taiwan are faced with deciding whether to have a child or not and the desire to maintain a certain level of quality of life. This decision was part of the process involved in balancing between having children and maintaining the quality of life.

Quality of life is very individual and there are a number of areas that this can relate to. For instance, many participants in this current study expressed that they planned to have their first child in the third year after they got married, so they can enjoy their life before having children. Similarly, Benzies and colleagues ${ }^{[31]}$ found in their study that one of reasons why women postponed childbearing was that they had to first satisfy their desire for travel. Moreover, a qualitative study in Taiwan explored the experiences of pregnant women over 35 years of age for the first time. ${ }^{[32]}$ Yang and colleagues ${ }^{[32]}$ found that these women were concerned about "whether they would regain their former free lifestyles". This demonstrated that having a spontaneous lifestyles was important for these women. However, this study ${ }^{[32]}$ does not discuss the reason why these women did not have their first child until they were over 35 years old.

The declining fertility rates reported in other East Asia countries has been explained as being due to economic development. ${ }^{[33]}$ It is becoming clear that this economic development specifically is related to materialistic values which has been shown to negatively influence the value people place on having children. The issue is that materialistic values become prevalent and require a lot of time and attention that then competes with having children. Materialism is present in much of the developed world but is reported to be stronger in East Asia. ${ }^{[33]}$ This is then all about owning the right goods and the fact that social status is measured by owning luxury goods. Social status is therefore driving materialism which in turn is negatively influencing the fertility rate. This is confounded by decreased job security which results in people investing in education and delaying starting families. ${ }^{[34]}$ In addition, there is a greater acceptance of attitudes towards couples not having children in many developed countries such as America. ${ }^{[35]}$ It is clear from this study that this in increasingly the case in Taiwan as well. These two factors have therefore contributed to the decrease in fertility rate in Taiwan. 
One of the strategies that women identified that they used to help them find the balance between quality of life and having children was finding ways to assist them to achieve this. One of the ways was through support in the form of childcare, emotional and financial assistance. Most Taiwanese women work full time and want to continue to do this after their child is born. Previously most Taiwanese lived in extended family environments with grandparents taking care of the children. More recently the nuclear family has dramatically increased to become the new norm. ${ }^{[36]}$ Traditional values appear to still be influencing women's decision to have a child, however, but not as strong as previously was the case. ${ }^{[37]}$ Maybe this belief towards traditional values and family support through the return of the extended family is something that could be capitalised on in helping to turn the fertility rate around. In addition, there needs to be some reform in the workplace to encourage more family friendly practices in order to change the culture and encourage women to have children.

The other component of the equation that was identified from the participants in this study was the increased materialistic values of the modern world. Helping people turn away from materialistic values has been shown to improve people's psychological wellbeing. ${ }^{[33]}$ Decreasing people's priority on materialistic goal has successfully been achieved by Kasser and colleagues ${ }^{[38]}$ who implemented a financial education program designed to help orientate adolescent children away from spending and towards sharing and saving. Part of this program was discussion on the distinction between needs and wants and promoting healthy money habits. This program could also include discussion on traditional values and the value of extended families and strategies to encourage this. Taiwan had undergone dramatic societal modernisation, extensive urbanisation and family denuclearisation in recent times, moving far away from traditional Taiwanese values. ${ }^{[39]}$ Future research exploring the effectiveness of such a program in turning the fertility rate around would be the next step.

This study, however, only interviewed women who had already chosen to have a child and could be considered a limitation of this study. Further studies interviewing women who have not yet decided to have a child would extent the knowledge further in this area. In addition, interviewing women at the end of their childbearing age who had decided not to have children is another area that needs exploration. Both of these were not within the scope of this research.

\section{Conclusion}

Taiwan had a very high fertility rate during the 1960s which resulted in an extensive family planning program being introduced. This had a strong influence in declining the birth rate which is currently too low. Taiwan is predicted to lead to zero population growth in the foreseeable future. This study aimed to gain an understanding of the personal, social and cultural factors influencing Taiwanese women's motherhood decision making by interviewing 34 first time mothers.

A number of categories were identified from the data with this paper presenting only the category of childbearing and the quality of life. Under this category a number of factors were identified that contributed to the decision on whether to have children. This included the couple's financial circumstances, existing pressure from living expenses, childbearing is costly and having children in a responsibility.

Childbearing and quality of life was identified from the data as a crucial factor influencing participant's decision making choices to have children. This was because women wanted to maintain a certain quality of life and needed to then ascertain how much this would be influenced by having children. It is becoming clear that economic development specifically related to materialistic values, has negatively influenced the value people place on having children. Encouraging a return to traditional Taiwanese values as well as orienting people away from materialistic values maybe a way to turn the fertility rate around. An education program that focuses on these aspects followed by an evaluation of the effectiveness would be the aim of future research in this area.

\section{ACKNOWLEDgements}

This work is part of Doctoral study undertaken through the Royal Melbourne Institute of Technology (RMIT) University. A note of appreciation goes to the participants for their time. Thanks also to the supervisors for supporting this research.

\section{Conflicts of InTEREST Disclosure}

The authors declare no conflicts of interest.

\section{REFERENCES}

[1] Lee SH, Kuo BJ. Chinese traditional childbearing attitudes and infertile couples in Taiwan. Journal of Nursing Scholarship. 2000; 32(1): 54. https://doi.org/10.1111/j.1547-5069.2000.00054.x

Published by Sciedu Press
[2] Cheung NF. Choice and control as experienced by Chinese and Scottish childbearing women in Scotland. Midwifery. 2002; 18(3): 200213. PMid:12381424. https://doi .org/10.1054/midw. 2002. 0315 
[3] Potter RG, Freedman R, Chow L. Taiwan's Family Planning Program. Science. 1968; 160(3830): 848-853. PMid:5689623. https : //doi.org/10.1126/science.160.3830.848

[4] Freedman R, Chang MC, Sun TH, et al. The fertility transition in Taiwan. In A. Thornton \& H. S. Lin (Eds.), Social change and the family in Taiwan. Chicago: University of Chicago Press. 1994. 264-304 p.

[5] Thornton A, Lin MY. Introduction. In A. Thornton \& M. Y. Lin (Eds.), Social Change and the family in Taiwan. Chicago: University of Chicago Press. 1994. 1-21 p.

[6] Department of Household Registration Affairs Ministry of the Interior Fertility rates of childbearing age women 1951-2011 Taiwan. Available from: http://sowf.moi.gov.tw/stat/year/elist.htm

[7] Chen R. Taiwan's population growth to be negative by 2025. The Taiwan Economic News. 2012. Available from: http://www. cens .com/cens/html/en/news/news_inner_40831.html

[8] Bureau of National Health Insurance, D.o.H., Executive Yuan, Taiwan. National Health Insurance in Taiwan 2012-2013 Annual Report. Taipei. 2013. Available from: http://www.nhi.gov.tw/Resource/webdata/13767_1_NHI_ 2012-2013\%20ANNUAL\%2OREPORT . pdf

[9] Feng JY, Han WJ. Maternity leave in Taiwan. Family Relations. 2010; 59(3): 297-312. PMid:21603074. https://doi.org/10.1111/j. $1741-3729.2010 .00603 . \mathrm{x}$

[10] Lin WI, Yang SY. From successful family planning to the lowest of low fertility levels: Taiwan's dilemma. Asian Social Work and Policy Review. 2009; 3(2): 95-112. https://doi.org/10.1111/ j.1753-1411.2009.00027.x

[11] Cernada G, Sun TH, Chang MC, et al. Taiwan's population and family planning efforts: An historical perspective. International Quarterly of Community Health Education. 2007; 27(2): 99-120. PMid:18364300. https://doi.org/10.2190/IQ.27.2.b

[12] Freedman R, Takeshita JY. Family planning in Taiwan: An experiment in social change. Princeton, New Jersey: Princeton University Press. 1969. https://doi.org/10.1515/9781400877416

[13] Chen YH. Trends in low fertility and policy responses in Taiwan. The Japanese Journal of Population. 2012; 10(1): 78-88.

[14] Chen YH. The significance of cross-border marriage in a low fertility society. Journal of Comparative Family Studies. 2008; 39(3): 331-352.

[15] Lee M. Transition to below replacement fertility and policy responses in Taiwan. The Japanese Journal of Population. 2009; 7(1): 71-86.

[16] Tsai HJ. Historical formation of population policy in Taiwan. Taiwanese Journal of Sociology. 2007; 39: 65-106.

[17] Cheung NF. The cultural and social meanings of childbearing for Chinese and Scottish women in Scotland. Midwifery. 2002; 18(4): 279-295. PMid:12473443. https://doi.org/10.1054/midw. 2 002.0328

[18] Khalaf I, Callister LC. Cultural Meanings of Childbirth. Journal of Holistic Nursing. 1997; 15(4): 373-388. https ://doi .org/10.1 $177 / 089801019701500405$

[19] Ganley J. Becoming a parent: the emotional journey through pregnancy and childbirth. Chichester, Eng: John Wiley \& Sons. 2004.

[20] Richardson D. Women, motherhood and childbearing. Basingstoke: Macmillan press. 1993.

[21] Creswell JW. Qualitative inquiry and research design: choosing among five approaches (3rd ed.). Los Angeles: Sage. 2013.

[22] Holloway I, Todres L. Grounded Theory. In K. Gerrish \& A. Lacey (Eds.), The research process in nursing (6th ed.). Chichester, West Sussex: Wiley-Blackwell Pub. 2010. 153-164 p.
[23] Draucker CB, Martsolf DS, Ross R, et al. Theoretical sampling and category development in grounded theory. Qual Health Research. 2007; 17(8): 1137-1148. PMid:17928484. https ://doi.org/10 $.1177 / 1049732307308450$

[24] Morse JM. Determing sample size. Qualitative Health Research. 2000; 10(1): 3-5. https://doi.org/10.1177/10497320012911 8183

[25] Corbin J, Strauss AL. Basics of qualitative research: Techniques and procedures for developing grounded theory (3rd ed.). London: Sage Publications. 2008. https://doi.org/10.4135/978145223015 3

[26] Davison GM, Reed BE. Culture and customs of Taiwan. Westport, Conn.: Greenwood Press. 1998.

[27] Tolke A, Diewald M. Insecurities in employment and occupatinal careers and their impact on the transition to fatherhood in Western Germany. Demographic Research. 2003; 9(3): 42-68.

[28] Chen CS, Liu TC, Chen LM. National health insurance and antenatal care use: a case in Taiwan. Health Policy. 2003; 64: 99-112. https://doi.org/10.1016/S0168-8510(02)00141-0

[29] Fu TH, Hughes R. New social risks and family change in Taiwan. In R. K. H. Chan, Takahashi \& L. L. R. Wang (Eds.), Risk and public policy in East Asia. England: Ashgate Publishing Limited. 2010. 75-88 p.

[30] Gustafsson S, Kalwij A. Fertility decisions: Economy theory, empirical analysis and policy relevance. In S. Gustafsson \& A. Kalwij (Eds.), Education and postponement of maternity: Economic analyses for industralized countries: Springer Netherlands. 2006; 15: 31-64. https://doi.org/10.1007/1-4020-4716-9

[31] Benzies K, Tough S, Tofflemire K, et al. Factors influencing women's decisions about timing of motherhood. J Obstet Gynecol Neonatal Nursing. 2006; 35: 625-633. PMid:16958718. https://doi.org/ 10.1111/j.1552-6909.2006.00079.x

[32] Yang YO, Peden-McAlpine $\mathrm{C}$, Chen $\mathrm{CH}$. A qualitative study of the experiences of Taiwanese women having their first baby after the age of 35 years. Midwifery. 2007; 23(4): 343-349. PMid:17229507. https://doi.org/10.1016/j.midw. 2006.03.009

[33] Li NP, Lim AJY, Tsai M, et al. Too materialistic to get married and have children? PLoS One. 2015; 10(5): 1-12. https ://doi.org/ 10.1371/journal.pone. 0126543

[34] Li NP, Patel L, Balliet D, et al. The incompatibility of materialism and the desire for children: psychological insights into the fertility discrepancy among modern countries. Social Indicators Research. 2011; 101(3): 391-404. https://doi.org/10.1007/s11205-0 10-9665-9

[35] Gubernskaya Z. Changing attitudes towards marriage and children in six countries. Sociological Perspectives. 2015; 53(2): 179-200. https://doi.org/10.1525/sop. 2010.53.2.179

[36] Hsueh CT. Diversity among families in contemporary Taiwan: Old trunks or new twigs? In D. L. Poston Jr, W. S. Yang \& D. N. Farries (Eds.), The family and social change in Chinese societies. New York: Springer. 2014. 35: 195-211.

[37] Chen SL. Exploring influences impacting on Taiwanese women's decision to have children: implications for nurses and midwives. $\mathrm{PhD}$ Thesis. RMIT University. 2015.

[38] Kasser T, Rosenblum KL, Sameroff AJ, et al. Changes in materialism, changes in psychological wellbeing: Evidence from three longitudinal studies and an intervention experiment. Motiv Emotion. 2013; 38(1): 1-22. https://doi .org/10.1007/s11031-013-9371-4

[39] $\mathrm{Lu} \mathrm{L}$. The transition to parenthood: Stress, resources and gender differences in a Chinese society. Journal of Community Psychology. 2006; 34(4): 471-488. https://doi .org/10.1002/jcop. 20110 